\title{
DIURNAL VARIATIONS OF CO 2 MIXING RATIO IN THE LOWER ATMOSPHERE BY THREE WAVELENGTH DIAL
}

\author{
Yasukuni Shibata, Chikao Nagasawa, Makoto Abo \\ Tokyo Metropolitan University, Hino, Tokyo 1910065, Japan \\ *Email: sibata@tmu.ac.jp
}

\begin{abstract}
We have conducted the measurement of high accurate $\mathrm{CO}_{2}$ mixing ratio profiles by measuring the temperature profiles simultaneously using the three wavelength $\mathrm{CO}_{2}$ DIAL. The measurements of $\mathrm{CO}_{2}$ diurnal variation in the lower atmosphere were carried out on sunny and cloudy days respectively. We find out that increasing of the $\mathrm{CO}_{2}$ mixing ratio occurs over the altitude of about $2 \mathrm{~km}$ from the surface during nighttime. On the other hand, the $\mathrm{CO}_{2}$ mixing ratio decreases over the lower atmosphere during daytime. In particular, the $\mathrm{CO}_{2}$ mixing ratio decreases earlier on sunny days than on cloudy days after sunrise. This result suggests that $\mathrm{CO}_{2}$ absorption by photosynthesis greatly contributes to the strength of the solar radiation.
\end{abstract}

\section{INTRODUCTION}

Validating and improving the global atmospheric transport model requires precise measurement of the carbon dioxide $\left(\mathrm{CO}_{2}\right)$ profile. In particular, knowledge of $\mathrm{CO}_{2}$ diurnal variation in the lower atmosphere is important for the elucidation of sinks and sources. We have developed a ground based direct detection three wavelength $1.6 \mu \mathrm{m}$ DIAL to achieve measurements of vertical $\mathrm{CO}_{2}$ concentration and temperature profiles in the atmosphere $^{1-3}$. In the DIAL observation, the temperature dependence of the $\mathrm{CO}_{2}$ mixing ratio due to the temperature dependence of the absorption cross section is $1.6 \mathrm{ppm} / \mathrm{K}$ near the ground and the air density in the atmosphere. This means that the difference between the model and the actual temperature profile greatly influences the accuracy of the $\mathrm{CO}_{2}$ mixing ratio. We carried out measurements of $\mathrm{CO}_{2}$ diurnal variations on the sunny and cloudy day. In this paper, we report on the details of $\mathrm{CO}_{2}$ diurnal variations and the differences in $\mathrm{CO}_{2}$ profiles due to weather.

\section{2. $\mathrm{CO}_{2}$ DIURNAL VARIATIONS}

The $\mathrm{CO}_{2}$ DIAL consists of an optical parametric generator (OPG) transmitter that excited by the LD pumped Nd:YAG laser. The on-line DFB seed laser onto the line center $(1572.992 \mathrm{~nm})$ by the wavelength control unit including $\mathrm{CO}_{2}$ reference cell. The off-line DFB seed laser $(1573.137 \mathrm{~nm})$ is operated by the free-run mode. The third DFB seed laser $(1573.040 \mathrm{~nm})$ for the temperature measurement is operated by the offset lock system. These seed lasers were connected to an optical fiber switch, and the switching speed is $2.5 \mathrm{~ms}$. The atmospheric backscatters were collected by a 250 $\mathrm{mm}$ telescope and was connected into the nearinfrared PMT module operated with an analog mode. We realized the $\mathrm{CO}_{2}$ concentration measurement for daytime by using the narrowband interference filter with $1.0 \mathrm{~nm}$ FWHM.

Atmospheric $\mathrm{CO}_{2}$ measurements were conducted from 0.39 to $2.5 \mathrm{~km}$ by the three wavelength DIAL at the Hino campus of Tokyo Metropolitan University $(35.7 \mathrm{~N}, 139.4 \mathrm{E})$. Figure 1 shows the time-height cross section of the $\mathrm{CO}_{2}$ mixing ratio with an integration time of 30 minutes. Japan was covered with high pressure during the observation period. It was fine and the wind was weak. $\mathrm{A} \mathrm{CO}_{2}$ gas sensor (LI-COR, LI-7500) was installed at the our lidar laboratory. $\mathrm{CO}_{2}$ mixing ratio between the ground and $0.39 \mathrm{~km}$ altitude were interpolated. The sunrise was 5:00LT and the sunset was 18:23LT.

$\mathrm{CO}_{2}$ mixing ratios increased from 22:00 LT on 21 April to 07:00 LT on 22 April at the altitude of 1.5 $\mathrm{km}$ or less. On the other hand, $\mathrm{CO}_{2}$ mixing ratios decreased during daytime (especially in the afternoon). Furthermore, the increase or decrease in $\mathrm{CO}_{2}$ mixing ratios occurs earlier in the lower layer than in the upper layer. Diurnal variations are attributable primarily to the natural photosynthetic and respiration cycle of vegetation and soils and to anthropogenic sources in urban areas. 
Figure 2 shows the time-height cross section of the $\mathrm{CO}_{2}$ mixing ratio on $30-31$ October, 2018. It was cloudy during DIAL measurement and the clouds were about $5 \mathrm{~km}$ altitude and the wind was weak. The sunrise was 6:01LT. After 10:00LT, background level increased and we could not continue the DIAL measurement. As in the case of Fig. 1, the $\mathrm{CO}_{2}$ mixing ratio at night time increased to an altitude of $1.5 \mathrm{~km}$, and the value was $410 \mathrm{ppm}$ or more. However, even after 2 hours from sunrise, the decrease in $\mathrm{CO}_{2}$ mixing ratio as shown in Fig. 1 was not measured. We consider that the weaker photosynthetic activity on cloudy days compared to sunny days is due to the difference in the decrease of the $\mathrm{CO}_{2}$ mixing ratio after sunrise.

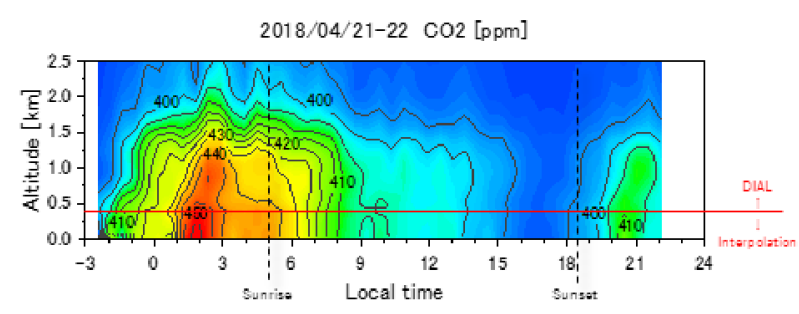

Figure 1 Time-height cross section of the $\mathrm{CO}_{2}$ mixing ratio on 21-22 April 2018 with an integration time of 30 minutes. Between the ground and the altitude of $390 \mathrm{~m}$, it is interpolated by the measurement of the ground $\mathrm{CO}_{2}$ sensor (LI-7500) and the DIAL measurement.

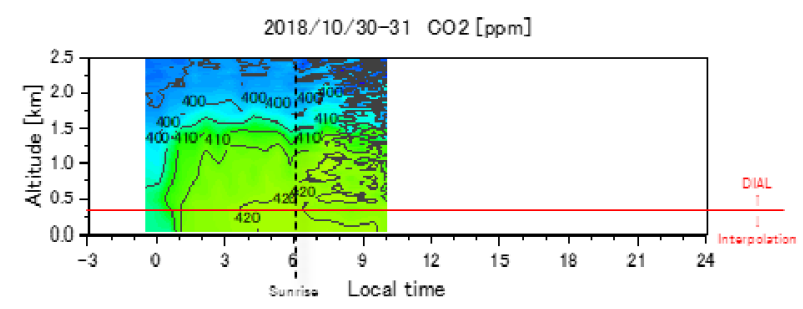

Figure 2 Time-height cross section of the $\mathrm{CO}_{2}$ mixing ratio on 30 - 31 April 2018.

\section{CONCLUSION}

We have developed the three wavelengths $1.6 \mu \mathrm{m}$ DIAL system for measurements of the $\mathrm{CO}_{2}$ mixing ratio and the atmospheric temperature profiles in the troposphere. The $\mathrm{CO}_{2}$ DIAL conducted measurements of a diurnal variation of $\mathrm{CO}_{2}$ mixing ratio and temperature profile on 21-22 April 2018 and 30-31 October 2018 from 0.39 to $2.5 \mathrm{~km}$ altitude. We can see that the increasing of $\mathrm{CO}_{2}$ mixing ratios occurs over the altitude of about $2 \mathrm{~km}$ from surface during nighttime. On a sunny day (April), the $\mathrm{CO}_{2}$ mixing ratio decreased significantly for two hours after sunrise. On the other hand, on a cloudy day (October), the $\mathrm{CO}_{2}$ mixing ratio did not decrease significantly even after two hours from sunrise. However, we could not continue the measurement except for four hours after sunrise due to the deterioration of the signalto-noise ratio of increase of background radiation arising from clouds over the lidar site, so we could not know the behavior of the $\mathrm{CO}_{2}$ mixing ratio over the entire daytime. Diurnal variations are attributable to the natural photosynthetic and respiration cycle of vegetation and soils and to anthropogenic sources in urban areas. However, we found out that $\mathrm{CO}_{2}$ mixing ratio in the lower atmosphere attributes primarily to the photosynthesis of plants under the environment around our lidar site.

\section{ACKNOWLEDGEMENTS}

This work was financially supported by the System Development Program for Advanced Measurement and Analysis of the Japan Science and Technology Agency.

\section{REFERENCES}

[1] D. Sakaizawa, et al., Appl. Opt. 48, 748-757 (2009).

[2] Y. Shibata, et al., Appl. Opt.,56, 1194-1201 (2017).

[3] Y. Shibata, et. al., Sensors 18, 4064 (2018). 